\title{
ANÁLISE ESPACIAL DE CONFLITOS DA ARBORIZAÇÃO DE VIAS PÚBLICAS: CASO IRATI, PARANÁ
}

\author{
Cleverson Luiz Dias Mayer ${ }^{1}$, Paulo Costa de Oliveira Filho ${ }^{2}$, Rogério Bobrowski ${ }^{2}$ \\ ${ }^{1}$ Prefeitura Municipal de Guarapuava, Guarapuava, Paraná, Brasil - cleverson_mayer@yahoo.com.br \\ ${ }^{2}$ Universidade Estadual do Centro-Oeste, Departamento de Engenharia Ambiental, Irati, Paraná, Brasil - paulocostafh@irati.unicentro.br; \\ bobrowski_roger@yahoo.com.br \\ Recebido para publicação: 12/11/2013 - Aceito para publicação: 19/05/2014
}

\begin{abstract}
Resumo
A arborização de vias públicas gera inúmeros benefícios à qualidade de vida da população urbana, mas se implantada de forma inadequada pode causar diversos transtornos. Nesse contexto, o objetivo desta pesquisa foi analisar os conflitos da arborização de vias públicas em Irati, Paraná, por meio de técnicas de análise espacial. Para isso, foi empregado o software SPRING, imagens orbitais Quickbird de $61 \mathrm{~cm}$ de resolução espacial e arquivos vetoriais contendo o limite dos bairros do município, a rede de distribuição elétrica, instalações subterrâneas, equipamentos urbanos e localização das árvores, fornecidos pela Secretaria de Ecologia e Meio Ambiente do Município. Após a estruturação do modelo de dados, foi realizada a confrontação das estruturas urbanas e a localização dos indivíduos arbóreos quanto às distâncias de segurança na realidade observada, por meio de consultas ao banco de dados, aplicando-se o estimador de densidade Kernel aos resultados. Com uso da estatística Kernel, foram geradas imagens de densidade referentes aos resultados das consultas, permitindo uma melhor interpretação visual na distribuição espacial dos conflitos.
\end{abstract}

Palavras-chave: Árvores de rua; estatística Kernel; geotecnologias; software livre.

\begin{abstract}
Spatial analysis of conflicts in street arborization: Irati case, Paraná. Street arborization promotes numerous benefits to urban population's life quality, however, if it is implanted in an inadequate way, street arborization can cause many disorders. In this sense, this research aim to analyze conflicts in Irati's urban forest, Paraná, by spatial analyses technique. In order to such analysis, we used SPRING software, Quickbird satellite's images of $61 \mathrm{~cm}$ spatial resolution, vector files containing boundary of city neighborhoods, electrical energy transmission system, sewer system and water distribution system, urban equipments and trees location provided by the Secretariat of Ecology and Environment of the City. After structuring the data model, we conducted the confrontation of urban structures and location of individual trees concerning safety distances to the reality observed into to the database, and then applied the Kernel density estimator to the results of consultations. With use of Kernel statistic, we generated density images from results of the consultations, which enable better visual interpretation in the spatial distribution of the conflicts.
\end{abstract}

Keywords: Roadside trees; kernel statistic; geotechnology; free software.

\section{INTRODUÇÃO}

A arborização urbana diz respeito a árvores e outras espécies de porte arbóreo (palmeiras e similares existentes dentro da urbe), plantadas em vias públicas, jardins ou parques, e em todo sistema de áreas verdes urbanas. Arborização viária representa as árvores ou as espécies arbóreas plantadas nas ruas, avenidas, canteiros centrais, calçadões, rotatórias, trevos, vias de parques, ciclovias e caminhos (FERRAZ; BENDINI, 2009).

A implantação e o desenvolvimento de áreas verdes nos centros urbanos desempenham funções sociais, econômicas e ambientais, sendo a arborização urbana cada vez mais valorizada como estratégia para aumentar o conforto ambiental (LIMA, 2009). Por conta disso, atribui-se à arborização urbana a oferta de benefícios como o controle da poluição atmosférica e sonora, a redução da radiação solar ao 
nível do solo e consequente redução da amplitude térmica, a diminuição do efeito de ilhas de calor, o aumento do valor dos imóveis e das propriedades e contribuição à saúde psicológica e social dos habitantes, entre outros (GREY; DENEKE, 1986; WALTON et al., 2008; NOWAK; GREENFIELD, 2008; NOWAK et al., 2008). De acordo com Bobrowski e Biondi (2012), esses benefícios podem ser provenientes de qualquer parte da planta (tronco, arquitetura de copa, folhas, floração e frutificação), entretanto é a partir da copa das árvores que surgem os principais benefícios almejados na arborização de vias públicas.

Segundo Schuch (2006), a arborização viária é essencial no arranjo de áreas verdes urbanas e cumpre importante papel na manutenção da qualidade ambiental das cidades. Sua importância é potencializada pela grande carência de áreas verdes em alguns bairros, isso devido aos espaços destinados à implantação de árvores se limitarem apenas às calçadas, pois os terrenos destinados à implantação de praças e jardins são quase inexistentes. O mesmo autor afirma que há limitações para a escolha de espécies, devido às dificuldades que se encontra pela concorrência de espaço nas calçadas, como redes de distribuição de água, gás e coleta de esgoto, postes, placas e fiação telefônica e elétrica.

Santos e Teixeira (2001) destacam como benefícios da arborização de vias públicas a ação purificadora (captação e/ou retenção de material particulado, adsorção e reciclagem de gases, contribuição para a melhoria da qualidade do ar), a redução dos níveis de ruído, o equilíbrio ambiental (conforto lúmnico, redução da temperatura proporcionada pela sombra das árvores e proteção da avifauna) e o conforto ambiental. Mesmo diante da importância de um sistema de arborização de vias públicas como parte do planejamento urbano, em muitos municípios observa-se a falta de um maior planejamento e atenção com esse assunto.

De acordo com Takahashi (1992), um plantio mal planejado é procedimento muito comum, causando vários prejuízos, como rompimento de fios de alta-tensão, interrupções no fornecimento de energia elétrica, entupimento de redes de esgoto e calhas, rachaduras em calçadas, obstáculos para circulação e acidentes envolvendo pedestres, veículo ou edificações.

Um dos principais problemas existentes na arborização viária de uma cidade é a "luta" ou conflito entre as árvores nas calçadas e as redes elétricas pelo mesmo espaço. Outro fato problemático diz respeito aos prejuízos e danos causados por podas malfeitas, podendo ocasionar a perda de estabilidade da árvore e consequente tombamento sobre casas, carros e fiações, o que traz transtornos de todo o tipo. Além disso, a poda em árvores urbanas é um dos principais motivos de perda do exemplar, sendo alto o número de árvores que morrem após tal operação (VELASCO, 2003).

Conforme a Companhia Paranaense de Energia (COPEL, s/d), as árvores plantadas recebem impactos ambientais de todas as formas, como galhos quebrados, podas em excesso e/ou indevidamente realizadas, falta de água devido às pequenas áreas para absorção hídrica e espécies inadequadas, entre outras. Na maioria das vezes, esses problemas são resultados da falta de uma orientação prévia e de um planejamento adequado para a arborização urbana.

Para a correção de eventuais problemas e na perspectiva de facilitar o planejamento da arborização, o Sistema de Informações Geográficas (SIG) possui um potencial de aplicação na descrição de dados espaciais a partir da realidade, além de permitir a correlação de objetos urbanos (rede elétrica, arborização urbana, sistema de saneamento subterrâneo e sinalização, entre outros) com a localização e agrupamento de informações sobre cada objeto (LIMA NETO et al., 2010).

Segundo Santos e Teixeira (2001), em relação aos problemas na arborização de vias públicas, os levantamentos qualitativos realizados em algumas cidades revelam as situações que comprometem o desenvolvimento satisfatório das espécies ao longo das vias públicas, dentre os quais se destacam as condições do solo, o tamanho das covas, a área livre, as podas, os poluentes do ar, a composição das espécies e a inadequação das espécies ao espaço e uso urbano. A estruturação de um banco de dados em ambiente SIG, por meio da espacialização das árvores e a geração de um banco de dados com informações relevantes para o planejamento da arborização urbana, possibilita analisar as relações entre as estruturas urbanas e a arborização de vias públicas, permitindo, assim, o desenvolvimento de técnicas de aperfeiçoamento de manejo, monitoramento da arborização, definição de prioridades nas intervenções, localização de novas áreas para o plantio, localização de árvores com necessidade de tratamento e elaboração de um programa de gerenciamento arbóreo.

Para Spadotto e Delmanto Júnior (2009), para o monitoramento das árvores implantadas nas vias públicas de uma cidade, dada a sua extensão territorial, as ferramentas de SIG vêm sendo muito utilizadas, pela rapidez, segurança e confiabilidade dos dados em análise. 
Justifica-se ainda a estruturação de um banco de dados em ambiente SIG como suporte ao planejamento e controle da arborização urbana pelo custo de implantação dessa metodologia, sendo muito menor do que o custo de futuras alterações nos sistemas de arborização viária devido à falta de planejamento (ADAM et al., 2001). Portanto, a partir da análise espacial dos dados, torna-se possível gerar informações espaciais para o planejamento da arborização viária, disponibilizando, assim, informações à comunidade e órgãos/instituições de fomento a esse serviço, com a finalidade de promover o conhecimento técnico-científico relacionado à arborização urbana (LIMA NETO et al., 2010).

Nesse contexto, a presente pesquisa foi realizada no centro da área urbana do município de Irati, Paraná, utilizando para isso os dados de inventário da arborização urbana obtidos na área estudada no período de janeiro a fevereiro de 2012, pelos autores da presente pesquisa, com o propósito de analisar as relações ou conflitos entre as árvores e as estruturas urbanas através de ferramentas de análise espacial, com o propósito de auxiliar o planejamento e gestão da arborização de vias públicas.

\section{MATERIAL E MÉTODOS}

\section{Localização da área de estudo}

O município de Irati, localizado na região centro-sul do estado do Paraná, no paralelo $25^{\circ} 27^{\prime} 56^{\prime \prime}$ de latitude sul com interseção com o meridiano 50 $37^{\prime} 51^{\prime \prime}$ de longitude oeste, a uma altitude de $812 \mathrm{~m}$ em relação ao nível do mar, a cerca de $150 \mathrm{~km}$ de Curitiba, capital do estado (Figura 1). A área do município é de $999,519 \mathrm{~km}^{2}$, com uma população de 56.207 habitantes, sendo 44.932 habitantes da área urbana $(79,94 \%)$ e 11.275 habitantes da área rural.

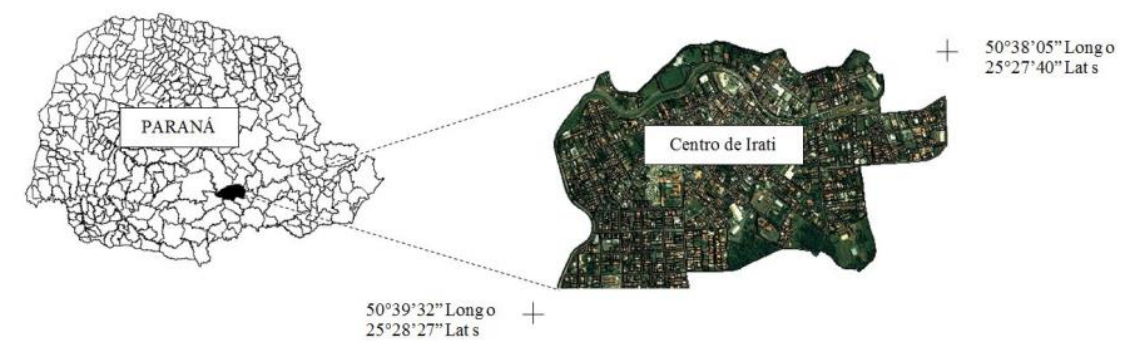

Figura 1. Localização geográfica da área de estudo.

Figure 1. Geographical location of the focused area.

Fonte: Elaborada pelos autores, 2013.

Para o desenvolvimento do presente estudo, foram utilizados os seguintes materiais: computador de boa performance e capacidade de disco e memória; software SPRING, versão 5.2, de domínio público e fonte aberta, disponível gratuitamente no site do Instituto Nacional de Pesquisas Espaciais (INPE); aplicativo Microsoft Excel; imagens orbitais Quickbird 2008 ortorretificadas e fusionadas com resolução espacial de $61 \mathrm{~cm}$ da área urbana do município de Irati, PR, fornecidas pela Prefeitura Municipal; arquivos vetoriais no formato DWG, contendo a base cartográfica com os limites dos bairros do município, eixo das ruas, meio-fio, nomenclatura das ruas, lotes, instalações subterrâneas, localização dos postes e das árvores, fornecidos pela Prefeitura Municipal; e dados do levantamento da arborização das vias públicas fornecidos pela Secretaria de Ecologia e Meio Ambiente de Irati, PR.

A estruturação do modelo de dados em ambiente SIG foi a primeira etapa do trabalho, sendo realizada por meio da importação e organização dos arquivos vetoriais e matriciais em suas respectivas categorias, no software SPRING, versão 5.2. Nesse processo, foram importados os seguintes arquivos vetoriais na categoria temática: limites dos bairros do município, eixo das ruas, meio-fio, nomenclatura das ruas, lotes, instalações subterrâneas, localização dos postes e das árvores. Na categoria imagem, foi realizada a importação das imagens orbitais que abrangem a área central urbana do município de Irati, PR. Posteriormente, foi realizado o recorte da área de interesse do trabalho, nesse caso, a área central do município.

Foi realizada a atualização das árvores existentes no arquivo vetorial contendo o posicionamento das árvores, por meio das imagens orbitais do satélite Quickbird. Esse trabalho foi realizado rua a rua, sendo que as árvores visualizadas nas imagens foram espacializadas por meio de vetorização sobre tela,

FLORESTA, Curitiba, PR, v. 45, n. 1, p. 11 - 20, jan. / mar. 2015. 
atualizando o arquivo vetorial que já continha a localização das mesmas, mas se encontrava desatualizado, com informações de aproximadamente 12 anos atrás.

Também foi levado em consideração o arquivo histórico do levantamento da arborização realizado pela prefeitura no ano de 2009, que continha as informações de todas as árvores existentes na data do levantamento, sendo, portanto, o mais atual. Para isso, comparou-se o número de árvores após a espacialização com os dados do levantamento in loco e comprovaram-se realmente quais árvores estavam presentes. Para associar as árvores espacializadas com os seus respectivos dados de levantamento de campo, utilizaram-se as seguintes informações: número do lote, distâncias de esquina, garagem e postes e espaçamento entre árvores. As árvores encontradas nas imagens, mas que não estavam no levantamento, foram marcadas como árvores retiradas, e as árvores que constavam no levantamento, mas não foram detectadas nas imagens, foram vetorizadas, e suas localizações estabelecidas utilizando como referências o número do lote à frente da árvore e as distâncias de esquina e postes, espaçamento entre árvores e garagem.

Os atributos utilizados para alimentar o banco de dados alfanumérico foram os do levantamento da arborização realizado pela prefeitura. A seguir, foi realizada a associação dos geo-objetos (árvores) ao banco de dados alfanumérico, possibilitando a geração de vários resultados sobre conflitos da arborização urbana local, utilizando-se o módulo de consultas por expressões lógicas e agrupamento de geo-objetos. Para uma melhor visualização e interpretação dos dados, foi realizada uma análise espacial pontual utilizando um estimador de densidade por Kernel quártico. A estimativa de densidade foi feita com o software SPRING versão 5.2. Conforme Câmara et al. (2004), uma alternativa simples para analisar o comportamento de padrões de pontos é estimar a intensidade pontual do processo em toda a região de estudo. Para isso, pode-se ajustar uma função bidimensional sobre os eventos considerados, compondo uma superfície cujo valor será proporcional à intensidade de amostras por unidade de área. Esta função realiza uma contagem de todos os pontos dentro de uma região de influência, ponderando-os pela distância de cada um à localização de interesse. O objetivo é a verificação de como a intensidade varia em toda a área de estudo, isto é, conferindo uma estimativa da densidade de probabilidade univariada ou multivariada a partir das observações, ou, em outras palavras, um histograma suavizado (BAILEY; GATRELL, 1995). O resultado é uma imagem com a estimativa da intensidade, cuja análise é feita de forma subjetiva, porém com a maior facilidade de padrões do que a simples visualização de um padrão pontual (POTTKER, 2012).

O estimador de intensidade por Kernel verifica, para cada localidade da área de estudo, o número e disposição dos indivíduos que ocorrem em um raio previamente estabelecido pelo pesquisador. A formulação matemática é dada pela equação 1 .

$$
\chi(\mathrm{s})=\frac{1}{\delta_{\tau}} \sum_{i=1}^{n} \frac{1}{\tau^{2}} \mathrm{k}\left(\frac{\left(s-s_{i}\right)}{\tau}\right)
$$

em que: $\chi(s)$ é a densidade de eventos por unidade de área;

$n$ é o número de indivíduos observados;

s representa uma localidade qualquer da área de estudo;

$\mathrm{s}_{\mathrm{i}}$ é a localidade dos $n$ eventos observados;

$\mathrm{k}$ é uma função de densidade de probabilidade bivariada, simétrica em relação à origem;

i é chamado de raio de influência (bandwidth) e é essencialmente o raio do círculo que terá como centro cada localidade;

fator $\delta_{\mathrm{i}}$ corrige distorções de bordadura, sendo determinado pela equação 2 .

$$
\delta_{\tau}(s)=\int_{A} \tau^{-2} \mathrm{k}\left(\frac{(s-u)}{\tau}\right) \mathrm{du}
$$

em que: $\delta_{\mathrm{r}}(\mathrm{s})$ constitui o volume sob o Kernel centrado em s que se situa dentro de A (BAILEY; GATRELL, 1995).

A figura 2 mostra a função Kernel realizando a contagem dos eventos de interesse dentro de uma região de influência, ponderando-os pela distância, de cada um, à localização de interesse, demonstrando que os principais fatores de interferência do pesquisador são quanto à função Kernel (função densidade de probabilidade) propriamente dita e ao valor $\tau$. 


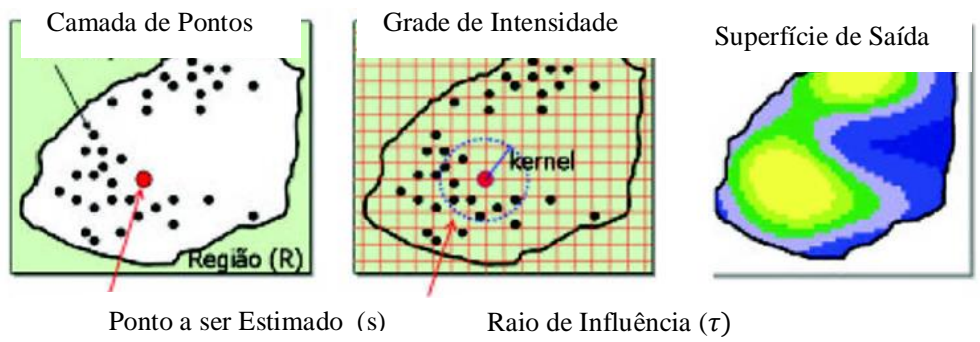

Figura 2. Passos para o cálculo de densidade de pontos segundo a técnica de Kernel.

Figure 2. Steps for density calculation of points using Kernel technique.

Fonte: Modificada de Brasil (2007).

Comumente, a função densidade de probabilidade usada pode ser uma função de terceira ou quarta ordem, como na equação 3.

$$
K(r)=\frac{3}{\pi}\left(1-r^{2}\right)
$$

Ou então uma função gaussiana, como na equação 4:

$$
\mathrm{K}(\mathrm{r})=\frac{1}{\sqrt{2 \pi}} e^{\left(\frac{r^{2}}{2}\right)}
$$

Para o Kernel quártico, a expressão torna-se a equação 5:

$$
\lambda(\mathrm{s})=\sum_{h_{i \leq \tau}} \frac{3}{\pi \tau^{2}} \mathrm{k}\left(1-\frac{h_{i}{ }^{2}}{\tau^{2}}\right)
$$

em que: $h_{i}$ é a distância entre o ponto s e a localização do evento observado;

$\mathrm{s}_{\mathrm{i}}$ e a soma só ocorre para os pontos que estão a uma localização $h_{i}$ que não ultrapasse $\tau$.

Bailey e Gatrell (1995) indicam como escolha sugerida a equação 6:

$$
\tau=0,68 n^{-0,2} \sqrt{R}
$$

Para estimar a intensidade quando a região $\mathrm{R}$ for um quadrado unitário, $\mathrm{n}$ será o número de eventos observados em R. Segundo os mesmos autores, essa sugestão pode ser estendida a regiões de estudo de outros formatos.

Após a geração das imagens pelo Kernel, foi aplicada a técnica de fatiamento, gerando uma imagem temática com 5 classes relacionadas à densidade de ocorrência de determinado conflito, sendo muito alto, alto, médio, baixo e muito baixo, possibilitando assim a visualização de um gradiente de variação de densidade dos agrupamentos.

\section{RESULTADOS E DISCUSSÃO}

Após a estruturação do modelo de dados no ambiente SIG, pôde-se visualizar as árvores encontradas e sua distribuição espacial no ambiente urbano (Figura 3). Através dessa visualização, foi possível observar a localização das árvores em relação a algumas estruturas urbanas, tais como postes de sinalização, lotes urbanos e canalização de água e esgoto, sendo estas de grande importância e responsáveis pelos principais problemas encontrados no planejamento e gestão da arborização de vias públicas.

Nesse sentido, destaca-se a localização das canalizações subterrâneas, muitas vezes deixadas de lado no planejamento de novos plantios, pela dificuldade de serem localizadas, mas de grande importância considerando os enormes problemas que podem causar devido à sua obstrução pelas raízes das árvores, o que pode gerar a interrupção no fornecimento de água e contaminação do solo. O gestor da arborização urbana pode visualizar a localização das canalizações subterrâneas com precisão e, assim, planejar melhor o plantio para evitar futuros conflitos. Dados sobre a altura da rede elétrica, a largura de calçadas e a dimensão de canteiros poderão ser incluídos no sistema e utilizados via consulta orientada ao 
objeto, para complementar o conjunto de informações de suporte a decisões sobre o manejo da arborização viária, sendo analisados em conjunto com os resultados apresentados pela estatística Kernel.

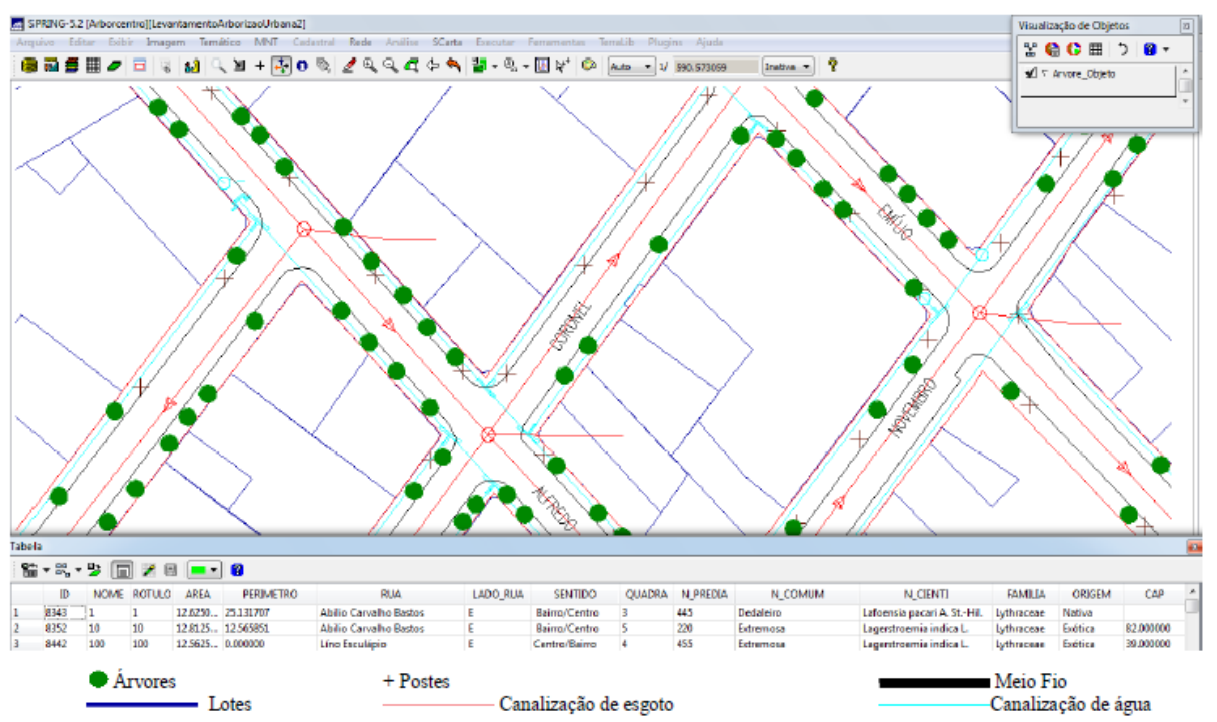

Figura 3. Visualização da base cartográfica utilizada no modelo de dados, contendo as árvores, lotes urbanos, postes de luz/eletricidade e rede de água e esgoto.

Figure 3. View of the cartographic base used in the data model, containing trees, urban lots, street lights/electricity and water network and sewage.

Para o cálculo da estimativa de densidade Kernel, foi considerada uma área ou retângulo envolvente de $2.116 .639 \mathrm{~m}^{2}$, que compreendia a região estudada, e posteriormente foram calculados os raios de influência para cada conjunto de dados, levando em consideração os diferentes números de eventos observados na região estudada (Tabela 1).

Tabela 1. Conjunto de dados demonstrando seus respectivos raios de influência $(\tau)$.

Table 1. Data set showing respective rays influence $(\tau)$.

\begin{tabular}{lcc}
\hline Conjunto de dados & Número de eventos (n) & Raio de influência (i) (metros) \\
\hline Indivíduos em conflito & 1286 & 236 \\
Conflito com primeira bifurcação & 883 & 255 \\
Conflito com próxima árvore & 864 & 256 \\
Conflito com área livre de calçada & 783 & 261 \\
Conflito com fiação aérea & 285 & 319 \\
Conflito com postes & 240 & 331 \\
Conflito com garagem & 169 & 355 \\
Conflito com mobiliário urbano & 113 & 384 \\
Conflito com caixas de inspeção & 87 & 405 \\
Conflito com placas de sinalização & 52 & 449 \\
\hline
\end{tabular}

Na figura 4, é apresentado o resultado do uso da estatística espacial através da estimativa de densidade Kernel aplicada à distribuição espacial de várias situações de conflito identificadas a partir de consultas por expressões lógicas. Essa estimativa, que transforma consultas lógicas a objetos em resultados de campos contínuos, evidencia os locais com maior densidade no número de conflitos, sendo representados pelas cores vermelho (densidade muito alta), laranja (densidade alta), amarelo (densidade média), verde (densidade baixa) e branco (densidade muito baixa).

A utilização desta técnica melhorou bastante a percepção da distribuição espacial dos diferentes conflitos, demonstrando com maior clareza os locais onde estes ocorrem com maior frequência dando suporte à tomada de decisão para um possível manejo. 

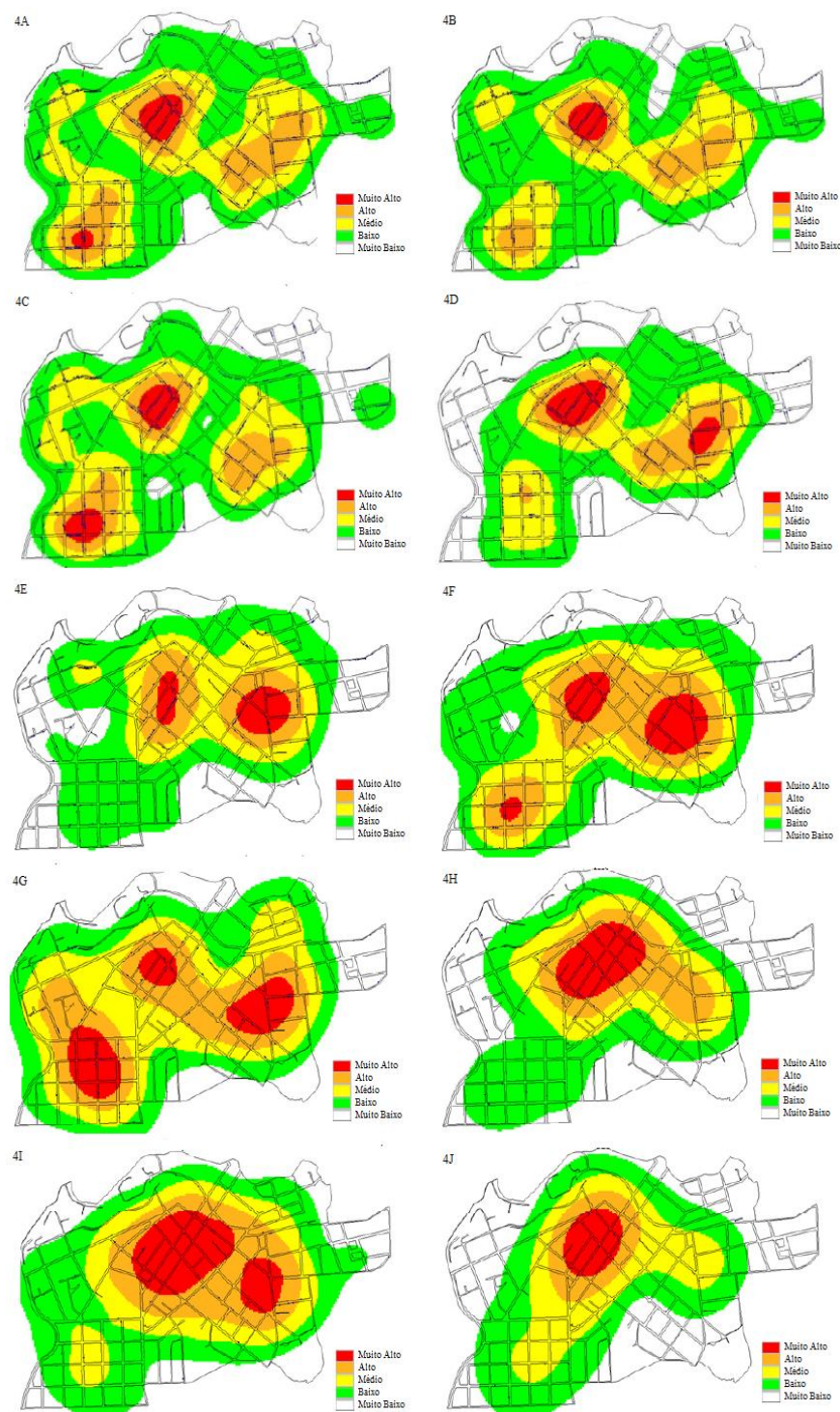

Figura 4. Estimativa de densidade Kernel quártico aplicada à distribuição espacial dos diferentes conflitos identificados com uso de consultas lógicas. 4A - Árvores com algum tipo de conflito; 4B - Árvores com altura da primeira bifurcação menor que 1,8 metros; 4C - Árvores com distância menor que 12 metros entre árvores; 4D - Árvores com área livre menor que $1 \mathrm{~m}^{2}$; 4E - Árvores com distância igual a zero metro da fiação aérea; 4F - Árvores com distância menor que 5 metros dos postes; $4 \mathrm{G}$ - Árvores com distância menor que 2 metros da entrada de garagem; 4H - Árvores com distância menor que 3 metros do mobiliário urbano; 4I - Árvores com distância menor que 3 metros das caixas de inspeção; 4J - Árvores com distância menor que 3 metros das placas de sinalização.

Figure 4. Quartic kernel density estimation applied to the spatial distribution of the different identified conflicts with use of logical queries. 4A - Trees with some kind of conflict; 4B - trees with height less than 1.8 meters first bifurcation; $4 \mathrm{C}$ - Trees with distance less than 12 meters between trees; 4D - Trees with less than $1 \mathrm{~m}^{2}$ free area; 4D - Trees with a distance of zero meters of overhead lines; $4 \mathrm{~F}$ - Trees with less than five meters away from the posts; $4 \mathrm{G}$ - Trees with distance less than 2 meters from the driveway; $4 \mathrm{H}$ - Trees with distance less than three meters of street furniture; $4 \mathrm{I}$ - Trees with distance less than three meters of manholes; $4 \mathrm{~J}$ Trees with distance less than three meters of road signs. 
A localização de indivíduos arbóreos em conflito com estruturas urbanas (Figura 4A) possibilitou a percepção de uma maior concentração de conflitos exatamente onde ocorre a maior quantidade de árvores. A aplicação do estimador para a informação sobre o maior número de árvores que apresentam altura da primeira bifurcação menor que $1,80 \mathrm{~m}$ (Figura 4B) demonstrou certa homogeneidade em sua distribuição, sendo constatado apenas um grupo, localizado na área mais central, com alta densidade. De acordo com Lima Neto et al.(2010), a altura de bifurcação abaixo de $1,80 \mathrm{~m}$ se constitui num problema ao trânsito livre dos pedestres nas calçadas. Em relação às árvores em canteiro com área livre menor que $1 \mathrm{~m}^{2}$ (Figura 4D), observou-se a formação de dois grupos distintos, com densidade muito alta de indivíduos. Isso é um fato desinteressante, pois quanto menor a área permeável nas calçadas, menor tende a ser a infiltração da água para aproveitamento pelas árvores e maior tende a ser o escoamento superficial, o que acaba por comprometer a drenagem urbana. Quanto às árvores com distância menor que 5 metros dos postes de iluminação ou rede elétrica (Figura 4F), foram detectados três grupos de concentração muito alta de indivíduos com esse tipo de conflito, sendo constatada uma quantidade alta de árvores mal posicionadas em relação aos postes. Para esse último caso, o conflito observado pode ser reflexo da falha administrativa em relação ao bem público, seja pela introdução de árvores muito próximas aos postes ou pela implantação de poste junto a árvores preexistentes.

De uma forma geral, essas informações mostram-se úteis à tomada de decisão, para que as ações sejam direcionadas para as áreas que demonstram maior quantidade de conflitos, otimizando o processo de gestão.

Para Silva Filho et al. (2002), o uso do banco de dados relacional para arborização de vias públicas é de grande importância, pois fornece informações sobre o entorno de onde o indivíduo arbóreo está inserido, possibilitando realizar cruzamento de informações, além de ser uma aplicação prática da informática, fornecendo diversificados relatórios para o manejo e auxílio ao cadastramento das árvores por meio de interface amigável.

Vários autores que utilizaram um SIG como ferramenta de avaliação e gestão da arborização de vias públicas concluíram que a aplicação e implementação desse sistema pode subsidiar a avaliação, monitoramento e planejamento da arborização (ALVAREZ et al., 2009; FALCE et al., 2012; FRANCO, 2006; GALLON et al., 2012; LIMA NETO et al., 2010; OLIVEIRA FILHO; SILVA, 2010; SCHUCH, 2006; SPADOTTO; DELMANTO JÚNIOR, 2009). Como demonstrado, pelas várias aplicações, o estimador de densidade Kernel mostrou-se uma ferramenta com alto potencial a ser explorado pelos pesquisadores ligados à área de arborização urbana, pois facilita a localização e análise pontual dos eventos pesquisados.

\section{CONCLUSÕES}

- A utilização do estimador de densidade Kernel permitiu modificar os resultados obtidos pelas consultas por expressões lógicas boleanas para resultados de campo contínuo, proporcionando uma melhor visualização da distribuição espacial da ocorrência dos conflitos.

- As consultas realizadas demonstraram um grande potencial do sistema se aplicado como ferramenta para o planejamento e gestão da arborização de vias públicas, possibilitando, ao gestor da arborização, realizar o cruzamento de informações relevantes ao manejo das árvores, principalmente na localização e no confronto entre indivíduos arbóreos e estruturas urbanas.

- O sistema implementado demonstrou grande potencial como ferramenta de gestão e auxílio na tomada de decisão sobre arborização das árvores de rua, podendo ser de grande utilidade para os gestores públicos.

\section{REFERÊNCIAS}

ADAM, E.; GUEDES JÚNIOR, A.; HOCHHEIM, N. Geoprocessamento para o inventário das espécies arbóreas na região de Florianópolis. In: GISBRASIL 2001, Curitiba. Anais... Curitiba: Fator GIS, 2001.

ALVAREZ, I. A.; OLIVEIRA, U. R.; CARVALHO, J. C. L.; TAURA, T. A. Uso de geotecnologias para subsidiar planos de ação da arborização viária do centro de Petrolina, PE. In: CONGRESSO BRASILEIRO DE ARBORIZAÇÃO URBANA: DIVERSIDADE NA FLORESTA E NA CIDADE: COLETÂNEA DE TRABALHOS. Anais... Rio Branco: Sociedade Brasileira de Arborização Urbana, 2009. 
BAILEY, T. C.; GATRELL, A. C. Interactive spatial data analysis. Harlow: Longman Scientific and Technical, 1995. $413 \mathrm{p}$.

BRASIL. Introdução à estatística espacial para a saúde pública. Brasília: Ministério da Saúde, 2007.

BOBROWSKI, R.; BIONDI, D. Distribuição e dinâmica da área de copa na arborização de ruas de Curitiba, Paraná, Brasil, no período de 1984-2010. Árvore, Viçosa, v. 36, n. 4, p. 625 - 635, 2012.

CÂMARA, G.; CARVALHO, M. S.; FUCKS, S.; MONTEIRO, A. M. Análise Espacial e Geoprocessamento. In: FUCKS, S.; CARVALHO, M. S.; CÂMARA, G.; MONTEIRO, A. M. (ORG.). Análise espacial de dados geográficos. Brasília: EMPRAPA, 2004.

COMPANHia paranaense de EnERgia ElÉtrica (COPEL). Copel e o Meio Ambiente: Como Arborizar sua cidade. Guia para os municípios. s/d-a.

FALCE, B. de O.; LEÃO, B. D. de A.; SOUZA, D. M. de; BENDA, F. Análise da distribuição espacial de árvores e arbustos quanto ao porte, à taxonomia e à utilização através de sistema de informação geográfica. Revista da Sociedade Brasileira de Arborização Urbana, Piracicaba, v. 7, p. 23 - 34, 2012.

FERRAZ, M. V.; BENDINI, H. N. Workshop sobre arborização urbana no Vale do Ribeira. Botucatu: FEPAF. 2009, 56 p.

FRANCO, V. S. M. Gerenciamento da arborização na área do campus da UFMG utilizando ferramentas SIG. 2006. 38 p. Trabalho de Conclusão de Curso (Especialização) - Universidade Federal de Minas Gerais, Belo Horizonte, MG.

GALlON, R.; MASCARENHAS, A. R. P.; SILVA, L. S.; DEMARQUI, E. N.; BARROS, L. M. O. Cadastramento da arborização presente em loteamentos no município de Sinop, MT. In: SIMPÓSIO BRASILEIRO DE CIÊNCIAS GEODÉSICAS E TECNOLOGIAS DA GEOINFORMAÇÃO, 4, 2012, Recife. Anais... Recife, 2012, p. 1 - 8.

GREY, G. W.; DENEKE, F. J. Urban Forestry. 2. ed. New York: J. Wiley, 1986. 199 p.

INSTITUTO NACIONAL DE PESQUISAS ESPACIAIS (INPE), 2009. Tutorial do Spring 5.2. Disponível em: <http://www.dpi.inpe.br/spring/portugues/manuais.html>. Acesso: 07 de nov. 2012.

LIMA NETO, E. M.; BIONDI, D.; ARAKI, H. Aplicação do SIG na arborização viária - unidade amostral em Curitiba, PR. In: SIMPÓSIO BRASILEIRO DE CIÊNCIAS GEODÉSICAS E TECNOLOGIAS DA GEOINFORMAÇÃO, 3, 2010, Recife. Anais... Recife, 2010. p. 01 - 06.

LIMA, R. M. C. Avaliação da arborização urbana do Plano Piloto. 2009. 84 p. Dissertação (Mestrado em Ciências Florestais) - Universidade de Brasília, Brasília, BR.

NOWAK, D. J.; CRANE, D. E.; STEVENS, J. C.; HOEHN, R. E.; WALTON, J. T.; BOND, J. A ground based method for assessing urban forest structure and ecosystem services. Arboriculture \& Urban forestry, Champaign, v. 34, n. 6, p. 347 - 358, 2008.

OLIVEIRA FILHO, P. C.; SILVA, S. V. K. Um sistema de informações para suporte espacial e de decisões à gestão da arborização urbana no município de Guarapuava, Paraná. Revista da Sociedade Brasileira de Arborização Urbana, Piracicaba, v. 5, n. 3, p. 82 - 96, 2010.

POTTKER, G. S. Distribuição espacial de espécies da Floresta Ombrófila Mista na Flona de Irati, Paraná. 2012. 96 p. Dissertação (Mestrado em Ciências Florestais) - Universidade Estadual do CentroOeste, Irati, PR.

SANTOS, N. R. Z.; TEIXEIRA, I. F. Arborização de vias públicas: ambiente x vegetação. Santa Cruz do Sul: Instituto Souza Cruz, 2001.

SCHUCH, M. I. S. Arborização urbana: uma contribuição à qualidade de vida com uso de geotecnologias. 2006. 102 p. Dissertação (Mestrado em Geomática) - Universidade Federal de Santa Maria, Santa Maria, RS. 
SILVA FILHO, D. F.; PIZETTA. P. U. C.; ALMEIDA, J. B. S. A.; PIVETTA, K. F. L.; FERRAUDO, A. S. Banco de dados relacional para cadastro, avaliação e manejo da arborização em vias públicas. Revista Árvore, Viçosa, MG, v. 26, n. 5, p. 629 - 642, 2002.

SPADOTTO, L. G. F.; DELMANTO JÚNIOR, O. Planejamento e gerenciamento da arborização urbana utilizando técnicas de geoprocessamento. Revista Tékhne e Lógos, Botucatu, v. 1, n. 1, 34 - 52, 2009.

TAKAHASHI, L. Y. Monitoramento e informatização da administração e manejo da arborização urbana. In: CONGRESSO BRASILEIRO SOBRE ARBORIZAÇÃO URBANA, 1992, Vitória. Anais... Vitória: PMV/SMMA, 1992.

VELASCO, G. D. N. Arborização viária X sistemas de distribuição de energia elétrica: avaliação dos custos, estudo das podas e levantamento de problemas fitotécnicos. 2003. 94 p. Dissertação (Mestrado) Escola Superior de Agricultura Luiz de Queiroz, Piracicaba, SP.

WALTON, J. F.; NOWAK, D. J.; GREENFIELD, E. J. Assessing urban forest canopy cover using airborne or satellite imagery. Arboriculture \& Urban Forestry, Champaign, IL, v. 34, n. 6, p. 334 - 340, 2008. 